determine the outcome of AIS patients with a low ASPECTS who undergo aspiration thrombectomy.

Materials and Methods This is a subset analysis of a global prospective multicenter registry (COMPLETE) that enrolled adults with large vessel occlusion AIS and a pre-stroke mRS of 0-1 who underwent first-line aspiration thrombectomy with the Penumbra System. Data for patients with ASPECTS 2-5 were compared across lower and higher ASPECTS, patient age, baseline collateral flow (ASITN/SIR grade), and time to puncture groups.

Results Of the 650 patients enrolled, 73 had ASPECTS 2-5. No significant difference was detected between ASPECTS 2-3 and ASPECTS $4-5, \leq 80$ and $>80$ years old, collateral flow groups, or $\leq 6$ and $>6$ hours to puncture for rates of mTICI $2 \mathrm{~b}-3$ post-procedure, mRS $0-2$ at 90 days, or symptomatic $\mathrm{ICH}$ at 24 hours. All-cause mortality rate at 90 days was significantly higher for ASPECTS 2-3 than for ASPECTS 4-5. There was a trend for higher sICH for time to puncture $>6$ hours $(\mathrm{p}=0.09)$. mRS $0-2$ at 90 days was achieved in only $18.8 \%$ of patients with ASITN $0-1$ and in no patients $>80$ years old.

Conclusion Even in AIS patients with low ASPECTS, aspiration thrombectomy treatment can achieve a good functional outcome in some patients and should be considered.

Disclosures J. Fifi: 1; C; Microvention, Penumbra, Stryker. 2; C; Microvention, Stryker. 4; C; Imperative Care. A. Hassan: 2; C; GE Healthcare, Genentech, Medtronic, Microvention,

\begin{tabular}{|c|c|c|c|c|c|c|}
\hline \multicolumn{7}{|c|}{ Abstract E-024 Table 1} \\
\hline & \multicolumn{3}{|c|}{ ASPECTS } & \multicolumn{3}{|c|}{ Patient age, years } \\
\hline & $\begin{array}{l}2-3 \\
(N=27)\end{array}$ & $\begin{array}{l}4-5 \\
(N=46)\end{array}$ & $\begin{array}{l}P \text { - } \\
\text { value }\end{array}$ & $\begin{array}{l}>80 \\
(\mathrm{~N}=9)\end{array}$ & $\begin{array}{l}\leq 80 \\
(\mathrm{~N}=64)\end{array}$ & $\begin{array}{l}\mathrm{P} \text { - } \\
\text { value }\end{array}$ \\
\hline $\begin{array}{l}\text { mTICI } 2 b-3 \text { post- } \\
\text { procedure }\end{array}$ & $88.9 \%$ & $87.0 \%$ & .999 & $88.9 \%$ & $87.5 \%$ & .999 \\
\hline mRS $0-2$ at 90 days & $28.0 \%^{*}$ & $34.1 \%^{\dagger}$ & .786 & $0.0 \%^{\S}$ & $35.0 \%{ }^{\ddagger}$ & .166 \\
\hline $\begin{array}{l}\text { All-cause mortality at } \\
90 \text { days }\end{array}$ & $44.4 \%$ & $15.2 \%$ & .012 & $22.2 \%$ & $26.6 \%$ & .999 \\
\hline $\begin{array}{l}\text { Symptomatic ICH at } 24 \\
\text { hours }\end{array}$ & $11.1 \%$ & $2.2 \%$ & .140 & $0.0 \%$ & $6.3 \%$ & .999 \\
\hline
\end{tabular}

${ }^{\star} \mathrm{N}=25 .{ }^{\dagger} \mathrm{N}=41 .{ }^{\S} \mathrm{N}=6 .{ }^{\ddagger} \mathrm{N}=60$

\begin{tabular}{|c|c|c|c|c|c|c|}
\hline & \multicolumn{3}{|c|}{$\begin{array}{l}\text { Baseline collateral flow } \\
\text { (ASITN/SIR grade) }\end{array}$} & \multicolumn{3}{|c|}{ Time to puncture, hours } \\
\hline & $\begin{array}{l}0-1 \\
(\mathrm{~N}=17)\end{array}$ & $\begin{array}{l}2-3 \\
(\mathrm{~N}=18)\end{array}$ & $\begin{array}{l}\mathrm{P} \text { - } \\
\text { value }\end{array}$ & $\begin{array}{l}>6 \\
(\mathrm{~N}=23)\end{array}$ & $\begin{array}{l}\leq 6 \\
(N=50)\end{array}$ & $\begin{array}{l}\mathrm{P} \text { - } \\
\text { value }\end{array}$ \\
\hline $\begin{array}{l}\text { mTICI 2b-3 post- } \\
\text { procedure }\end{array}$ & $76.5 \%$ & $77.8 \%$ & .999 & $91.3 \%$ & $86.0 \%$ & .710 \\
\hline mRS $0-2$ at 90 days & $18.8 \% \%^{\pi}$ & $30.8 \%^{\#}$ & .667 & $38.1 \%{ }^{* \star}$ & $28.9 \% " 1$ & .572 \\
\hline $\begin{array}{l}\text { All-cause mortality at } \\
90 \text { days }\end{array}$ & $17.6 \%$ & $16.7 \%$ & .999 & $17.4 \%$ & $30.0 \%$ & .390 \\
\hline $\begin{array}{l}\text { Symptomatic ICH at } 24 \\
\text { hours }\end{array}$ & $5.9 \%$ & $5.6 \%$ & .999 & $13.0 \%$ & $2.0 \%$ & .090 \\
\hline
\end{tabular}

${ }^{91} \mathrm{~N}=16 .{ }^{*} \mathrm{~N}=13 .{ }^{* *} \mathrm{~N}=21 .{ }^{\|} \mathrm{N}=45$.
Penumbra, Stryker, Cerenovus, Viz.ai, Balt, Scientia. 3; C; GE Healthcare, Genentech, Medtronic, Microvention, Penumbra, Stryker, Cerenovus, Viz.ai, Balt, Scientia. O. Zaidat: 1; C; Genentech, Medtronic Neurovascular, Stryker. 2; C; Codman, Medtronic Neurovascular, National Institutes of Health StrokeNet, Penumbra, Stryker. 4; C; Galaxy Therapeutics, Inc.

\section{E-025 ASPIRATION THROMBECTOMY OF ACUTE ISCHEMIC STROKE PATIENTS WITH INTRACRANIAL ATHEROSCLEROTIC DISEASE OR TANDEM LESION}

${ }^{1} \mathrm{O}$ Zaidat* ${ }^{2}{ }^{2} \mathrm{Fifi},{ }^{3,4} \mathrm{~A}$ Hassan. ${ }^{1}$ Mercy Health St. Vincent Medical Center, Toledo, OH; ${ }^{2}$ Icahn School of Medicine at Mount Sinai, New York, NY; ${ }^{3}$ University of Texas Rio Grande Valley, Harlingen, TX; ${ }^{4}$ Valley Baptist Medical Center, Harlingen, TX

\subsection{6/neurintsurg-2021-SNIS.121}

Introduction/Purpose The purpose of this study was to evaluate the safety and efficacy of aspiration thrombectomy in acute ischemic stroke (AIS) patients with anterior circulation tandem lesion.

Materials and Methods Patients with anterior circulation tandem lesion were extracted from a global prospective multicenter registry (COMPLETE) that enrolled 650 adults with large vessel occlusion AIS and a pre-stroke modified Rankin Scale score (mRS) of 0-1 who underwent aspiration thrombectomy with the Penumbra System. The primary efficacy endpoints were successful post-procedure angiographic revascularization (modified thrombolysis in cerebral infarction [mTICI] score of 2b-3) and good 90-day functional outcome (mRS of $0-2$ ). The primary safety endpoint was 90-day all-cause mortality. Outcomes of patients who received versus did not receive a stent were also compared.

Results The COMPLETE study enrolled 55 patients with anterior circulation tandem lesion; 20 of those patients received a stent and 35 patients did not. Successful revascularization was achieved in $89.1 \%$ of patients, and good functional outcome at 90 days was achieved in $63.5 \%$ of patients. The 90 -day allcause mortality rate was $7.3 \%$. The symptomatic intracranial hemorrhage $(\mathrm{ICH})$ rate at 24 hours was $7.3 \%$. Good 90-day functional outcome was achieved in $72.2 \%$ of patients with a stent and in $58.8 \%$ of patients without a stent $(\mathrm{P}=.34)$. The mortality rate at 90 days was $10.0 \%$ in patients with a stent and $5.7 \%$ in patients without a stent $(\mathrm{P}=.56)$. The symptomatic $\mathrm{ICH}$ rate 24 hours was $5.0 \%$ in patients with a stent and $8.6 \%$ in patients without a stent $(\mathrm{P}=.62)$.

Conclusion Aspiration thrombectomy was effective in restoring blood flow and resulting in good 90-day functional outcome in AIS patients with anterior circulation tandem lesion, and the 90-day mortality rate in these patients was low. No significant difference in outcomes was detected between patients with a stent and patients without a stent.

Disclosures O. Zaidat: 1; C; Genentech, Medtronic Neurovascular, Stryker. 2; C; Codman, Medtronic Neurovascular, National Institutes of Health StrokeNet, Penumbra, Stryker. J. Fifi: 1; C; Microvention, Penumbra, Stryker. 2; C; Microvention, Stryker. 4; C; Imperative Care. A. Hassan: 2; C; GE Healthcare, Genentech, Medtronic, Microvention, Penumbra, Stryker, Cerenovus, Viz.ai, Balt, Scientia. 3; C; GE Healthcare, Genentech, Medtronic, Microvention, Penumbra, Stryker, Cerenovus, Viz.ai, Balt, Scientia. 